\title{
Household Food Insecurity and Nutritional Status of Under- Five Children and Women of Reproductive Age from Pond Fish Farming Households in Sidama Zone, Southern Ethiopia: Community Based Cross-Sectional Study
}

\author{
Yohannes Kifle*, Alemneh Kabeta and Derese Tamiru \\ Department of Psychiatry, College of Health Sciences, Axum University, Aksum, Ethiopia
}

\begin{abstract}
Food insecurity is defined as situation that exists when all people, at all times, have no physical, social and economic access to sufficient, safe and nutritious food that meets their dietary needs and food preferences for an active and healthy life. Fish farming plays an important role in food security and nutrition by providing food and income. The aim of this study was to assess household food insecurity status and nutritional status of under-five children and women of reproductive age from pond fish farming households in Sidama Zone, Southern Ethiopia. The entire under five children ( $\mathrm{n}$ $=39)$ and reproductive age women's $(n=56)$ and households $(n=81)$ who produce fish using pond within the targeted; Woreda's of Sidama zone were purposively selected based on the availability of pond fish. The data of household food insecurity status, anthropometric measurements, focus group discussion and key informant interviews were conducted. Epi info version 7 was used for data entry. SPSS version 20 was used for data analysis. Food insecurity experience scale was used to describe the household's food insecurity status. Anthropometric indices HAZ, WAZ and WHZ were calculated by using WHO Anthro 2007. The main findings of the discussion summarized manually by narrating techniques. The finding shows that more than half of $(64 \%)$ the study households were from food secured. Regarding the nutritional status (17.9\%), (12.8\%) and (5.2\%) children were stunted, wasted and underweight respectively and $98.2 \%$ and $1.8 \%$ of reproductive age women BMI were within the normal range (BMI $18.5-24.9 \mathrm{~kg} / \mathrm{m}^{2}$ ) and below the normal range $\left(<18.5 \mathrm{~kg} / \mathrm{m}^{2}\right)$ respectively. Pond Fish farming has a contribution to household food security, Child and woman nutritional status through generating additional income which increases their purchasing power for other food groups and direct consumption of fish from their own pond.
\end{abstract}

Keywords

Nutritional status, Pond fish farming, Food Insecurity

\section{Introduction}

The production of fish and fisheries worldwide is approximately 154 million tons per year, and its consumption is $18.5 \mathrm{~kg}$ per year [1]. Annual fish production in Ethiopia has ranged between 13 and $29 \mathrm{MT}$ (million tons) per year over the last decade. The country in the lower end of fish consumers among the African countries (where the average is $9.4 \mathrm{~kg}$ ). According to FAO estimates, fish consumption in Ethiopia for the year 2009 was estimated at $0.2 \mathrm{~kg}$. Food insecurity (is) a "situation that exists when all people, at all times, have no physical, social and economic access to sufficient, safe and nutritious food that meets their dietary needs and food preferences for an active and healthy life [2,3]. According to latest FAO estimates, in 2017 , close to $10 \%$ of the world population "was exposed to severe food insecurity. Food insecurity is a critical challenge in Ethiopia, which is Africa's second populous country after Nigeria [4]. Under nutrition still persists in the vast majority of the world's poorest countries, affecting in particular women and children, Ethiopia ranked first in having the highest number of people in state of undernourishment which is 32.1 million people in 2014 [5]. Fish plays an important role for food security and nutrition by providing food and income [6]. Aquaculture interventions can contribute to improving nutritional status of households [7].

*Corresponding author: Yohannes Kifle, Department of Psychiatry, College of Health Sciences, Axum University, Aksum, Ethiopia

Accepted: September 26, 2020

Published online: September 28, 2020

Citation: Kifle Y, Kabeta A, Tamiru D (2020) Household Food Insecurity and Nutritional Status of Under-Five Children and Women of Reproductive Age from Pond Fish Farming Households in Sidama Zone, Southern Ethiopia: Community Based Cross-Sectional Study. J Hum Nutr 4(1):106-111 
Citation: Kifle Y, Kabeta A, Tamiru D (2020) Household Food Insecurity and Nutritional Status of Under-Five Children and Women of Reproductive Age from Pond Fish Farming Households in Sidama Zone, Southern Ethiopia: Community Based Cross-Sectional Study. J Hum Nutr 4(1):106-111

The effect can be direct, through within-household consumption and dietary improvement, but also indirect, through sale of fish produce and purchase of other food items (often at lower unit value than the sold fish) [8]. In Southern Ethiopia, since 2003 E.C. farmers had constructed ponds and started fishing production in their own farms. Right now more than 200 farmers in the Sidama zone of southern Ethiopia were producing fish using constructed ponds on their farms. This was increasing the availability and consumption of the fish by the households. The justification of assessing the household food insecurity and nutritional status of under-five children and women of reproductive age in a pond fish farming household were important for further action to increase the fish production, consumption and to decrease household food insecurity, to improve nutritional status of child and women in pond fish farming household. However, in Sidama Zone less justification was collected about pond fish farming activities decrease the household food insecurity, to improve nutritional status of child and women in pond fish farming household.

\section{Materials and Methods}

\section{Description of the study area}

This study was conducted at two selected woreda's of Sidama Zone Southern Ethiopia. The study woreda's were based on the availability of pond fish farming practices. These woreda's were Dara and Wensho from Sidama Zone.

Dara is one of the woredas of the Sidama Zone. Dara was bordered on the South by the Gedio Zone and on either side of it of the Oromia Region, on the Northwest by Chuko Town, on the North by Aleta Wendo Town, and on the northeast by Hula Town. Dara include Kebado and Teferi Kela Towns. Based on the 2007 Census conducted by the (CSA, 2007), the woreda has a total population of 155,265 of whom 76,475 are men and 78,790 are women; 10,660 or $6.87 \%$ of its population are urban dwellers.

In this woreda, currently there are 13 kebeles with more than 51 Pond fish farming and among these 38 of them started fish production. These kebeles are: Alemkoricha, Teramaj, Gelewacho, Satangala, Badessa, Orate, Shilcho, Shoicho, Setamo, Buna Tewaba, Loya, Kumato and Safa. Wensho is one of the woredas of the Sidama Zone located in the Great Rift Valley; Wensho was bordered on the Southwest by Aleta Wendo Town, on the West by Dale woreda, on the North by Shebedino woreda, on the Northeast by Gorche woreda, and on the Southeast by Bursa woreda. Wensho was separated from Dale woreda. Based on the 2007 Census conducted by the CSA, this woreda has a total population of 89,662 of whom 45,562 are men and 44,100 are women; 2,039 or $2.27 \%$ of its population are urban dwellers. In this woreda, currently there are five kebeles with more than 30 pond fish farming $\mathrm{HH}$ and among these 15 of them started fish production. These kebeles are: Hunkute, Fero, Bokaso, Alekena and Kinante.

\section{Instruments}

Semi-structured questionnaires were designed about household food insecurity status, nutritional status of under five children and reproductive age women's. Fish consump- tion frequency was measured using a two-point category scale and coded in descending order as follows: (1) More than once a year, (2) once a year irrespective of WHO. The result was categorized into two patterns of fish consumption: Fish Eaters (the respondents that consumed fish at once or more than once servings per a year) and Non-Fish Eaters (the respondents that not consumed fish) this was also irrespective of WHO.

In addition to the quantitative data collection focused group discussion and key informant interviews were used to gather the community fish consumption practices, barriers and facilitator's of fish consumption and overall information about fish in the study area respectively. Anthropometric assessments, height and weight were used to assess the nutritional status of under five children and reproductive age women's. Weight was measured using an electronic scale (Seca 770) with worn a light cloth of known weight during the measurement. The instrument was checked and adjusted to zero for each measurement. Sliding board to the nearest $0.1 \mathrm{~cm}$ gradation was used in measuring recumbent length for less than 2-years-old and height boards (Shorr measuring board) without shoes to the nearest $0.1 \mathrm{~cm}$ gradation was used in measuring standing height for greater than 2-yearsold.

\section{Quantitative data collection}

In this study, data were obtained by face-to-face interviews for gathering socio-demographic characteristics, household food insecurity information's by data collectors with the supervision of the supervisors and anthropometric measurements done by the researchers with supervisors. So as to avoid observer variation using calibrated equipment and standardized techniques.

\section{Qualitative data collection}

A focused group discussion (with men and women who had pond fish) with 8 minimum and 12 maximum participants with 2 group from fish farming and key informant interviews (agricultural workers) were done by the researchers with supervisors who were native speakers of the local language (Sidamigna) and Amharic.

\section{Data management and analysis}

The data was fed to Epi info version 7 computer software programs to make them ready for analysis by SPSS version 20 computer software program. House hold food insecurity experience scale was used to describe the household's food insecurity status. A total of 53 women of reproductive age were interviewed for the barriers and opportunities of fish consumption.

The focus group discussions were first transcribed in Sidamigna and Amharic by the two supervisors who can speak the local language and Amharic and translated into English by the principal investigator. The transcription and the notes taken during the discussions were used to identify main concepts. The main findings of the discussion, which was different from the survey results, were selected and summarized manually by narrating techniques. Anthropometric indices HAZ, WAZ, 
Citation: Kifle Y, Kabeta A, Tamiru D (2020) Household Food Insecurity and Nutritional Status of Under-Five Children and Women of Reproductive Age from Pond Fish Farming Households in Sidama Zone, Southern Ethiopia: Community Based Cross-Sectional Study. J Hum Nutr $4(1): 106-111$

WHZ were calculated by using the WHO 2006 multi center growth reference data using the computer program WHO Anthro 2007. Being stunted, underweight, and wasted were defined by Z-scores for HAZ, WAZ, and WHZ less than -2 standard deviations below median values was used to calculate the nutritional status of under five children and BMI was used to calculate the nutritional status of reproductive age women's. To gather the community's belief and fish consumption practices, fish consumption barriers and facilitators and benefits of fish farming with men and women who had pond fish farming.

\section{Ethical considerations}

Approval of the research was given by Hawassa University Institutional Review. The nature of the study was fully explained to the participants to obtain their oral consent. Data obtained from each study participant was kept confidential.
No discrimination was made if the participant wanted to withdraw from participating in the research.

\section{Results}

\section{Socio-demographic characteristics of the HHs}

Nearly all (98.8\%) of the head of the households were men (father) and $91.4 \%$ of the age of both (men and women) head were between 28 and 50 years old. The majority (64.2\%) of the household have 4-5 family size. Main occupations $(93.8 \%)$ of the head of households were farmer. All (100\%) of the head of households were married. More than three fourth $(88 \%)$ of the head of households were protestant. The majority $(91.4 \%)$ of the head of households were from the Sidama ethnic group. More than half (64.2\%) of the educational status of the head of the households were primary schools and $(2.5 \%)$ were illiterate (Table 1$)$.

Table 1: Socio-demographic characteristics of the HHs in the study area 2019.

\begin{tabular}{|c|c|c|c|}
\hline \multicolumn{2}{|l|}{ Variables } & \multirow{2}{*}{\begin{tabular}{|l} 
Frequency \\
74 \\
\end{tabular}} & \multirow{2}{*}{\begin{tabular}{|l|} 
Percent \\
91.4 \\
\end{tabular}} \\
\hline Age & $28-50$ yrs & & \\
\hline & $>50$ yrs & 7 & 8.6 \\
\hline & Total & 81 & 100.0 \\
\hline \multirow[t]{4}{*}{ Family Size } & $1-3$ & 13 & 16.0 \\
\hline & $4-5$ & 52 & 64.2 \\
\hline & $6-7$ & 16 & 19.8 \\
\hline & Total & 81 & 100.0 \\
\hline \multirow[t]{3}{*}{ Occupational Status } & Farmer & 76 & 93.8 \\
\hline & GO/NGO & 3 & 3.7 \\
\hline & Merchant & 2 & 2.5 \\
\hline \multirow[t]{3}{*}{ Head of the household } & Mother & 1 & 1.2 \\
\hline & Father & 80 & 98.8 \\
\hline & Total & 81 & 100.0 \\
\hline \multirow[t]{5}{*}{ Religion } & Orthodox & 8 & 9.9 \\
\hline & Muslim & 1 & 1.2 \\
\hline & Catholic & 1 & 1.2 \\
\hline & Protestant & 71 & 87.7 \\
\hline & Total & 81 & 100.0 \\
\hline \multirow[t]{3}{*}{ Ethnicity } & Sidama & 74 & 91.4 \\
\hline & Oromo & 4 & 4.9 \\
\hline & Total & 81 & 100.0 \\
\hline \multirow[t]{6}{*}{ Educational status } & Not educated & 2 & 2.5 \\
\hline & Primary school & 52 & 64.2 \\
\hline & Secondary school & 17 & 21.0 \\
\hline & Certificate (training) & 1 & 1.2 \\
\hline & Diploma/Degree & 9 & 11.1 \\
\hline & Total & 81 & 100.0 \\
\hline
\end{tabular}

Categorical data are presented as a proportion (frequency and percent). 
Citation: Kifle Y, Kabeta A, Tamiru D (2020) Household Food Insecurity and Nutritional Status of Under-Five Children and Women of Reproductive Age from Pond Fish Farming Households in Sidama Zone, Southern Ethiopia: Community Based Cross-Sectional Study. J Hum Nutr $4(1): 106-111$

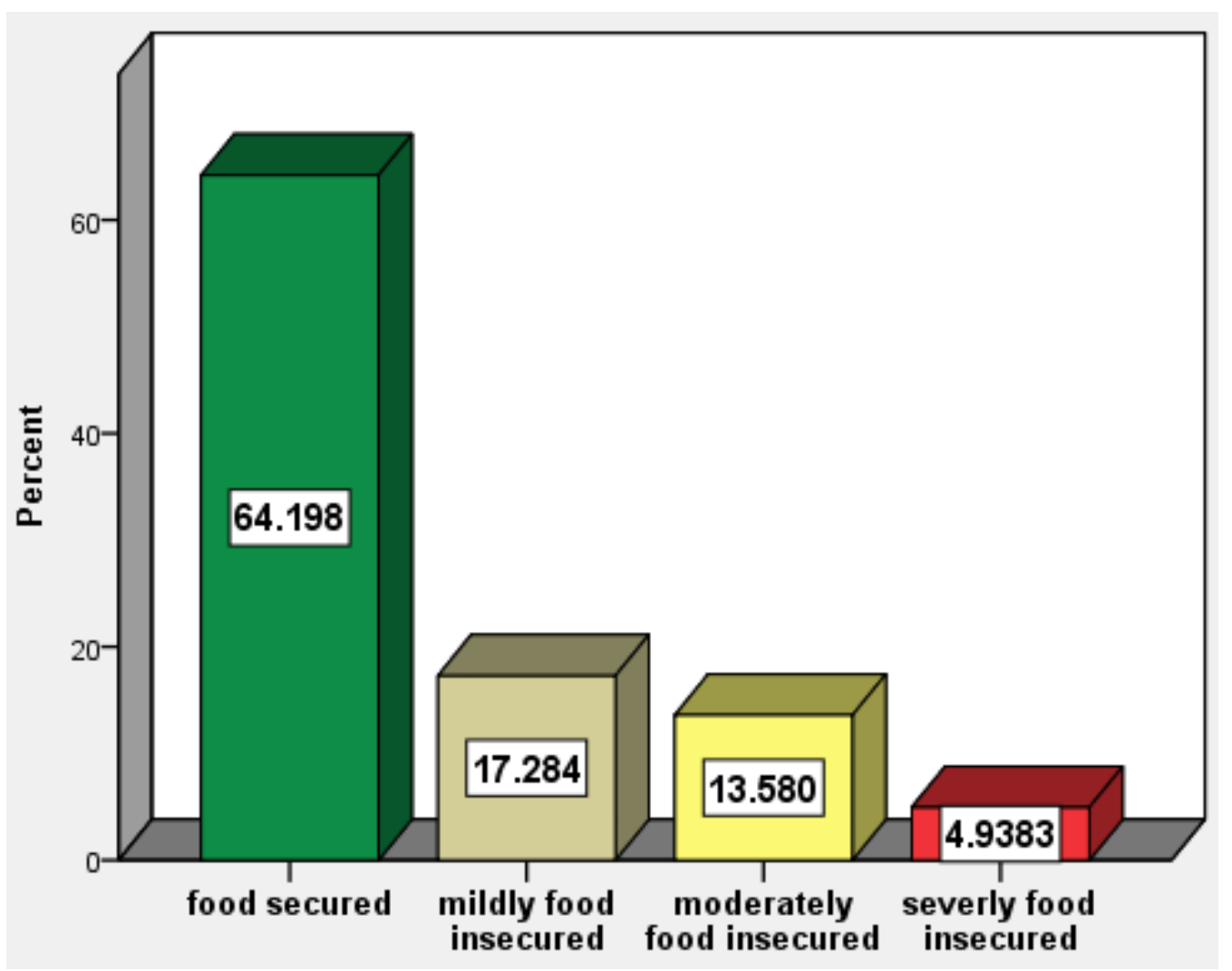

Figure 1: Food security status of the household in the study area 2019.

Table 2: Women's perception on pond fish farming to HHS food security 2019.

\begin{tabular}{|l|l|l|l|}
\hline \multicolumn{2}{|l|}{ Variables } & Frequency & Percent \\
\hline \multirow{3}{*}{ Women's perception } & Agreed & 75 & 92.6 \\
\cline { 2 - 4 } & Strongly agreed & 1 & 1.2 \\
\hline & Disagreed & 5 & 6.2 \\
\hline & Total & 81 & 100.0 \\
\hline
\end{tabular}

\section{Household food insecurity status in the study} Area

The finding shows that, more than half $(64.2 \%)$ of the study households were food secured and the rest $35.8 \%$ were food insecured. From the food insecured households, 17.3\%, $13.6 \%$ and $4.9 \%$ were mildly, moderately and severely food insecure respectively based on Food Insecurity Experience Scale (FIES) (Figure 1).

\section{Women's perception on pond fish farming to HHFS}

Almost (92.6\%) of woman's perception were agreed on the contribution of pond fish farming to household food security (Table 2).

\section{Barriers and facilitators to fish consumption among reproductive age women's}

Fish consumption among reproductive age women's, various factors make it "very difficult" to consume fish once and more than once per a year were, "Fish Availability, Self Efficacy (not good at determining the quality of fish) and Fish eating habits" as vocalized by reproductive age women's (Table 3 ).

\section{Nutritional status of under five children}

Anthropometric measurement of children, the Mean \pm SD of $\mathrm{W} / \mathrm{H}, \mathrm{H} / \mathrm{A}$ and $\mathrm{W} / \mathrm{A}$ were $1.2 \pm 0.4,1.1 \pm 0.3$, and 1.1 \pm 0.2 respectively. Regarding their nutritional status, $17.9 \%$ severely stunted, $41 \%$ were normal (Z-score -1 SD to +1 SD) and $41.1 \%$ were over-nourished for their/H/A. $12.8 \%$ were wasted and $87.2 \%$ were normal (Z-score -1 SD to +1 SD) for their $\mathrm{W} / \mathrm{H}$. Similarly, 5.2\% were underweight and $94.8 \%$ were normal (Z-score -1 SD to +1 SD) for their W/A (Table 4).

\section{Nutritional status of reproductive age women's in the study area}

Anthropometric measurements of reproductive age women's, $55.6 \%$ of their weight were between $55.1-60 \mathrm{~kg}$. Whereas $69.9 \%$ of their height were between $145-160 \mathrm{~cm}$. Regarding their nutritional status, $98.2 \%$ and $1.8 \%$ of reproductive 
Citation: Kifle Y, Kabeta A, Tamiru D (2020) Household Food Insecurity and Nutritional Status of Under-Five Children and Women of Reproductive Age from Pond Fish Farming Households in Sidama Zone, Southern Ethiopia: Community Based Cross-Sectional Study. J Hum Nutr 4(1):106-111

age women's BMI were within the normal BMI range (BMI $\left.18.5-24.9 \mathrm{~kg} / \mathrm{m}^{2}\right)$ and below the normal BMI $\left(<18.5 \mathrm{~kg} / \mathrm{m}^{2}\right)$ respectively (Table 5).

\section{Focused group discussion and key informant in- terview results}

They told the following benefits for the household. Since they started pond fish farming, they harvest fish one to two times a year. By selling fish, they generate additional income and by using the water from the ponds they started to grow different vegetables. These increased purchasing of other food groups and growing different vegetables helps the households for consumption of different food groups besides

Table 3: Barriers and facilitators to fish consumption among WRA in the study area $(n=53)$.

\begin{tabular}{|c|c|c|c|}
\hline \multicolumn{2}{|l|}{ Variables } & \multirow{2}{*}{\begin{tabular}{|l} 
Frequency \\
31 \\
\end{tabular}} & \multirow{2}{*}{\begin{tabular}{|l} 
Percent \\
58.5 \\
\end{tabular}} \\
\hline Fish availability & YES & & \\
\hline & NO & 22 & 41.5 \\
\hline & Total & 53 & 100.0 \\
\hline \multirow[t]{3}{*}{ Price perception } & YES & 21 & 39.6 \\
\hline & NO & 32 & 60.4 \\
\hline & Total & 53 & 100.0 \\
\hline \multirow{3}{*}{$\begin{array}{l}\text { Self efficacy (not good at } \\
\text { determining the quality of } \\
\text { fish) }\end{array}$} & YES & 29 & 54.7 \\
\hline & NO & 24 & 45.3 \\
\hline & Total & 53 & 100.0 \\
\hline \multirow[t]{3}{*}{ Convenience perception } & YES & 25 & 47.2 \\
\hline & NO & 28 & 52.8 \\
\hline & Total & 53 & 100.0 \\
\hline \multirow[t]{3}{*}{ Fish eating habits } & YES & 41 & 77.4 \\
\hline & NO & 12 & 22.6 \\
\hline & Total & 53 & 100.0 \\
\hline \multirow[t]{3}{*}{ Health beliefs } & YES & 25 & 47.2 \\
\hline & NO & 28 & 52.8 \\
\hline & Total & 53 & 100.0 \\
\hline \multirow[t]{3}{*}{ Sensory perception } & YES & 16 & 30.2 \\
\hline & NO & 37 & 69.8 \\
\hline & Total & 53 & 100.0 \\
\hline
\end{tabular}

Categorical data are presented as a proportion (frequency and percent). direct fish consumption which indirectly contributes to improve household food security and nutritional status.

\section{Discussion}

The aim of this study was to assess the household food insecurity status and child and women nutritional status in Sidama Zone, Southern, Ethiopia. The finding shows that more than half $(64.2 \%)$ of the study households were food secured and the rest $(35.8 \%)$ were food insecured. From the foodinsecured households, (17.3\%), (13.6\%) and (4.9\%) were mildly, moderately and severely food insecure respectively. This finding is supported by study done in western Kenya which state, most household heads reported that fish farming used as a way of producing high quality food, either for their families or for the market, and as a way of earning extra income, these enabled many fish farmers to reduce the number of months in which they faced serious food shortages [8] and study also done in Nigeria, fish contributes significantly to urban food security by increasing purchasing power at individual or household level., it was gathered that the main reason for most of the farmers' involvement in raising fish is to ensure food security at household level [9]. Similarly, study done in Cambodia Small-scale pond fish farming holds considerable potential to improve nutrition, enhance household food security and supplement household incomes through the sale of fish [10]. Almost (92.6\%) of woman's perception were agreed

Table 5: Anthropometric measurement and nutritional status of WRA in the study area 2019.

\begin{tabular}{|l|l|l|l|}
\hline Variables & Frequency & Percent \\
\hline \multirow{4}{*}{ Weight } & $45-50 \mathrm{~kg}$ & 11 & 19.6 \\
\cline { 2 - 4 } & $50.1-55 \mathrm{~kg}$ & 9 & 16.1 \\
\cline { 2 - 4 } & $55.1-60 \mathrm{~kg}$ & 30 & 53.6 \\
\cline { 2 - 4 } & $>60 \mathrm{~kg}$ & 6 & 10.7 \\
\cline { 2 - 4 } & Total & 56 & 100.0 \\
\hline \multirow{3}{*}{ Height } & $145-160 \mathrm{~cm}$ & 39 & 69.6 \\
\cline { 2 - 4 } & $161-175 \mathrm{~cm}$ & 17 & 30.4 \\
\cline { 2 - 4 } & Total & 56 & 100.0 \\
\hline \multirow{3}{*}{ BMI } & $<18.5 \mathrm{~kg} / \mathrm{m}^{2}$ & 1 & 1.8 \\
\cline { 2 - 4 } & $18.5-25 \mathrm{~kg} / \mathrm{m}^{2}$ & 55 & 100.0 \\
\cline { 2 - 4 } & Total & 56 & \\
\hline
\end{tabular}

Categorical data are presented as proportion (frequency and percent).

Table 4: Nutritional status of under five children in the study area 2019.

\begin{tabular}{|c|c|c|c|c|c|c|c|c|c|c|}
\hline \multirow[t]{3}{*}{ Variables } & \multicolumn{10}{|c|}{ Z-Score } \\
\hline & \multicolumn{2}{|c|}{$<-3 \mathrm{SD}$} & \multicolumn{2}{|c|}{$<-2 S D$} & \multicolumn{2}{|c|}{$-1 \mathrm{SD}$ to $+1 \mathrm{SD}$} & \multicolumn{2}{|c|}{$>+1 \mathrm{SD}$} & \multicolumn{2}{|c|}{$>+2$} \\
\hline & $N$ & $\%$ & $N$ & $\%$ & $N$ & $\%$ & $N$ & $\%$ & $N$ & $\%$ \\
\hline L/ht-for-age & 2 & 5.1 & 5 & 12.8 & 16 & 41 & 12 & 30.8 & 4 & 10.3 \\
\hline Wt-for-L/ht & 2 & 5.1 & 3 & 7.7 & 34 & 87.2 & & & & \\
\hline Weight-for-age & 1 & 2.6 & 1 & 2.6 & 37 & 94.8 & & & & \\
\hline
\end{tabular}

Categorical data are presented as a proportion (z-score and percent). 
Citation: Kifle Y, Kabeta A, Tamiru D (2020) Household Food Insecurity and Nutritional Status of Under-Five Children and Women of Reproductive Age from Pond Fish Farming Households in Sidama Zone, Southern Ethiopia: Community Based Cross-Sectional Study. J Hum Nutr 4(1):106-111

on the contribution of pond fish farming to household food securit While conducting the surveys on barrier and facilitator to fish consumption, the most common factors were Fish Availability, Self Efficacy (not good at determining the quality of fish) and Fish eating habits as vocalized by WRA.

The result of current finding revealed that, the anthropometric measurement of children, the mean $\pm \mathrm{SD}$ of $\mathrm{H} / \mathrm{A}, \mathrm{W} / \mathrm{H}$ and W/A were $1.2 \pm 0.4 \mathrm{SD}, 1.1 \pm 0.3 \mathrm{SD}$, and $1.1 \pm 0.2 \mathrm{SD}$ respectively. Anthropometric measurement of children, the Mean \pm SD of $W / H, H / A$ and $W / A$ were $1.2 \pm 0.4,1.1 \pm 0.3$, and $1.1 \pm 0.2$ respectively. Regarding their nutritional status, $17.9 \%$ stunted, $41 \%$ were normal (Z-score -1 SD to +1 SD) and $41.1 \%$ were over-nourished for their $\mathrm{L} / \mathrm{Ht} /$ Age. $12.8 \%$ were wasted and $87.2 \%$ were normal (Z-score -1 SD to +1 SD) for their W/H. Similarly, 5.2\% were underweight and $94.8 \%$ were normal (Z-score -1 SD to +1 SD) for their W/A Similarly, the study done in Salima, Malawi supported that the nutritional status of under- five children in the fishing community had no case of severe malnutrition and $10 \%$ of the children had moderate malnutrition whilst $90 \%$ of the children had a normal nutrition status [11].

Anthropometric measurement of reproductive age women's, the minimum and maximum of weight, height, and BMI of women's were $46 \mathrm{~kg}$ and $64 \mathrm{~kg}, 154 \mathrm{~cm}$ and $164 \mathrm{~cm}$ and $18.20 \mathrm{~kg} / \mathrm{m}^{2}$ and $24.4 \mathrm{~kg} / \mathrm{m}^{2}$ respectively. Regarding their nutritional status, $98.2 \%$ and $1.8 \%$ of reproductive age women's $\mathrm{BMI}$ were within the normal BMI range (BMI $18.5-24.9 \mathrm{~kg} /$ $\left.\mathrm{m}^{2}\right)$ and below the normal $\mathrm{BMI}\left(<18.5 \mathrm{~kg} / \mathrm{m}^{2}\right)$ respectively. The present finding is supported by the study done in Zambia, More than half of the mothers $(59.4 \%, n=423)$ were within the normal BMI range (BMI 18.5-25 kg/m²) [12].

\section{Conclusion}

The finding shows that, while household pond fish as a subsistence product have a direct contribution to household food security, child and women nutritional outcome, the generation of incomes derived from fish selling have more an indirect contribution to household food security, child and women nutritional outcome. With regards to barriers and facilitators for fish consumption among womens of reproductive age (WRA), the current finding clearly revealed that, Fish availability, Self- efficacy (not good at determining the quality of fish) and Fish eating habits were common barriers and facilitators from womens of reproductive age (WRA) and events like, fasting, inputs access and knowledge were common barriers and facilitators from focused group discussion (FGD) in the study area.

\section{Acknowledgements}

The authors acknowledge those who were made possible in this thesis. We thank to the Hawassa University School of Nutrition, Food Sciences and Technology for their support and facilitation. We would like to extend our thanks to Office of Vice President for Research and Technology, Research Program Directorate for funding data collection costs.

\section{Author's Contributions}

Yohannes Kifle is principal investigator, designed the study, took part in the data collection process, entered and analysed and wrote the first draft of this manuscript. Alemneh Kabeta \& Derese Tamiru oversaw the whole data collection processes, entered and analysed data and wrote the manuscript. Three of the authors read and approved the final manuscript.

\section{Funding}

The thesis study was funded by Hawassa University as a part of Thematic Research.

\section{Computing Interests}

All authors declare that they have no competing interests.

\section{References}

1. Ferit Mehmet, Aytekin Günlü, Hayriye Yeşim Can (2015) Fish consumption preferences and factors influencing it. Food Science and Technology 35: 339-346.

2. Isaac Tebogo Rampedi, Solomon ZittaWuyep (2018) Urban fish farming in jos nigeria contributions towards employment opportunities income generation and poverty alleviation for improved livelihoods. Agriculture 8: 110.

3. Mohamed Abdulahi (2017) Food security situation in Ethiopia: A review study. International Journal of Health Economics and Policy 2: 86-96.

4. Faoun (2018) The state of food securityand nutrition in the world.

5. Hlpefsn (2014) Sustainable fisheries and aquaculture for food security and nutrition.

6. Kawarazuka, Nozomi, Béné, Christophe (2010) Linking smallscale fisheries and aquaculture to household nutritional security

7. Prein Mark, Ahmed Mahfuz (2000) Integration of aquaculture into smallholder farming systems for improved food security and household nutrition. Food and Nutrition Bulletin 21.

8. Janko Assefa Mitike (2014) Fish production, consumption and management in Ethiopia. Research Journal of Agriculture and Environmental Management 3: 460-466.

9. Tunde Afolabi Monisola (2017) Motivations for involvement in urban catfish farming and sustainable food security in nigeria. 236-245.

10. Richardson Robert, Suvedi Murari (2018) Assessing the potential for small-Scale aquaculture in Cambodia. Environments 5:76.

11. Mzengereza Mlauzi (2017) Contribution of fish consumption to reduction of malnutrition among the under-five children in salima, Malawi. Journal of Animal Research and Nutrition

12. Marinda Pamela A, Genschick Sven, Khayeka Wandabwa Christopher, et al. (2018) Dietary diversity determinants and contribution of fish to maternal and underfive nutritional status in Zambia. PLoS One 13: e0204009. 